\title{
Efficacy and Safety of Ultrasound Guided Vacuum-Assisted Excision of Fibroadenomas: A Systematic Review
}

\author{
Tajudeen A. Wahab1 ${ }^{*}$, Botond K. Szabó ${ }^{2}$, Maher Jumah'1, Dalia Elfadl1, Kasim Behranwala ${ }^{3}$, \\ Inga Chen 1
}

${ }^{1}$ Elm Breast Care Centre, Department of Surgery, King George Hospital, Barking, Havering and Redbridge University Hospitals NHS Trust, London, England

${ }^{2}$ Elm Breast Care Centre, Department of Radiology, King George Hospital, Barking, Havering and Redbridge University Hospitals NHS Trust, London, England

${ }^{3}$ Department of Surgery, Wycombe Hospital, High Wycombe, England

Email: *oroki40@yahoo.com

How to cite this paper: Wahab, T.A., Szabó, B.K., Jumah, M., Elfadl, D., Behranwala, K. and Chen, I. (2017) Efficacy and Safety of Ultrasound Guided VacuumAssisted Excision of Fibroadenomas: A Systematic Review. Open Journal of Radiology, 7, 95-102.

https://doi.org/10.4236/ojrad.2017.72011

Received: April 26, 2017

Accepted: June 12, 2017

Published: June 15, 2017

Copyright () 2017 by authors and Scientific Research Publishing Inc. This work is licensed under the Creative Commons Attribution International License (CC BY 4.0).

http://creativecommons.org/licenses/by/4.0/

\begin{abstract}
Background: Ultrasound-guided, vacuum-assisted excision [UGVAE] of fibroadenomas is an emerging minimally invasive procedure. UGVAE is being increasingly employed by breast radiologists and surgeons. It has been approved for this use since 2006 by the National Institute for Health and Clinical Excellence in the UK. The aim of this systematic review is to evaluate the efficacy and safety of this procedure based on the up to date available evidence. Methods: A comprehensive literature search of the Cochrane library, Medline, Embase, PubMed, Google scholar, Trip-database, Internet, and the reference lists of relevant articles was performed. We searched for literature with sizeable cases of therapeutic vacuum-assisted excision of fibroadenomas. All prospective studies with more than 20 study participants were screened. The study quality was assessed using the Grading of Recommendations Assessment, Development, and Evaluation [GRADE] approach. All were in English. Results: Of the four case series that fulfilled the inclusion criteria there were 516 patients in which 520 procedures were performed. Overall complete excision rate was $89.4 \%$. In two of the studies, this was $100 \%$ when the lesions were less than $1.5 \mathrm{~cm}$ but reduced to $61 \%$ when between 1.5 and $2 \mathrm{~cm}$. Most common significant complication was bleeding with 2 cases of pneumothorax. None of the studies can be regarded as high quality going by GRADE approach. Conclusion: Within the limit of the current published case series, UGVAE appears to be an effective and safe procedure for excision of small fibroadenomas of less than $15 \mathrm{~mm}$ in size. A well designed case control study or randomized controlled trials with a sufficient sample size is needed to further
\end{abstract}


assess its safety, effectiveness and more importantly, patients' satisfaction especially in larger sized fibroadenomas.

\section{Keywords}

Ultrasound-Guided, Vacuum-Assisted Excision, Benign Breast Disease, Fibroadenoma

\section{Introduction}

Breast fibroadenomas (FA) are a common cause of a benign discrete palpable lump in females [1]. They are relatively more common in patients aged between 15 and 35 years. They often present as a painless mobile breast lump which are discovered incidentally in the majority of cases by the patients themselves. They can also be discovered during investigations for other breast conditions or during routine screening imaging or examination. They may either remain static, continue to grow or decrease in size. Some do disappear especially after menopause [2]. There is no clear cut clinical evidence that a simple fibroadenoma becomes malignant but there are reports of foci of breast cancer, especially LCIS, in some excised FA [3]. Patients with complex fibroadenomas had a significantly greater risk of breast cancer than those with simple ones [4]. This may be either in the index breast or the contralateral. A retrospective review of 2062 image guided core biopsy proven FA by Sander and Sara [5] found only 12 cases [0.58\%] that demonstrated atypia, in situ or invasive cancer either within or adjacent to the FA.

Traditionally, diagnosis of FA is established through triple assessment, which includes clinical evaluation, imaging (ultrasound scan [USS], mammogram or Magnetic Resonance Imaging [MRI]) and pathology (core biopsy or fine needle aspiration cytology [FNA]). If the diagnosis is confirmed to be a simple FA, treatments include conservative treatment in the form of reassurance with no need for further attendance in most patients, further follow-up and imaging or surgical excision, especially in older patients ( $>35$ years), large size $(>3 \mathrm{~cm})$ or complex FA. Based on their study, Dixon et al. [6] found conservative management of FA safe and acceptable to the majority of patients under the age of 40 years.

With improved resolution and image quality of ultrasound machines, the current national guideline for managing patients with breast symptoms in the UK considers it unnecessary to biopsy a FA in patients younger than 25 years of age if the ultrasound examination reveals a solid lesion with benign features (e.g. ellipsoid shape, wider than tall, well-defined outline with smooth edges, fewer than four gentle lobulations and homogeneous internal structure) [7].

When excision is indicated, either based on the multidisciplinary team (MDT) recommendation or patient's preference, open surgical excision remains the gold standard. There are ongoing efforts to develop minimally invasive techniques (MIT) that will be effective, safe, cosmetically acceptable and cost effective as a replacement for open excision. Available MIT includes ultrasound-guided high- 
intensity focused ultrasound (HIFU) [8], interstitial laser ablation [9], cryotherapy [10] and ultrasound-guided vacuum biopsy system [11]. The latter was approved by the UK National Institute for Clinical Excellence (NICE) [12] in 2006 based on the available literature then.

The aim of the present paper is to perform a systematic review of the up-todate studies on the efficacy and safety of ultrasound-guided vacuum-assisted biopsy system in excision of FA.

\section{Literature Search and Synthesis}

A comprehensive literature search of the Cochrane library, Medline, Embase, PubMed, Google scholar, Trip-database, and the Internet was conducted. We also searched the reference lists of relevant articles .We combined the MeSH terms "vacuum-assisted" "breast biopsy" "excision biopsy" "needle biopsy", "fibroadenoma", "breast fibroadenoma",

Forty-eight (48) records from the literature were identified. These were further screened by two of the authors to select those that meet the inclusion criteria. The third author is involved in case any disagreement. Data was extracted from the included studies for analysis.

The quality of the available evidence was graded according to the Grading of Recommendations Assessment, Development, and Evaluation (GRADE) approach. In "GRADE" observational studies and case series/case reports are by default graded as low quality and very low quality respectively [13].

Data was extracted from the four studies that met the inclusion criteria listed below. They were all prospective case series with no randomized controlled trials (RTC) identified in the search.

\subsection{Inclusion Criteria}

- Study type-RCT, meta-analysis or case series.

- Publication-English.

- Breast lesion treated-Fibroadenoma.

- No of subjects-Minimum of 20.

- Mode of diagnosis-Mammogram+/-USS+/-MRI with FNA or core biopsy.

- Length of Follow up-Minimum six months.

- Primary outcome-Excision rate, complications were recorded.

- Secondary outcome-Recurrence Rate.

- Imaging at follow up-Yes.

\subsection{PRISMA Flow Diagram [14] (Figure 1)}

Four studies met the inclusion criteria [15] [16] [17] [18]. There were a combined total of 516 patients who had had excision of 520 fibroadenomas performed with the use of an ultrasound-guided vacuum assisted biopsy device. The patients' age ranged from 17 - 91 years while the size of the treated fibroadenomas ranged from $5-60 \mathrm{~mm}$ (average $11.8 \mathrm{~mm}$ ). All had preoperative ultrasound, mammogram or combination of the two and preoperative cytology or tissue diagnosis. 

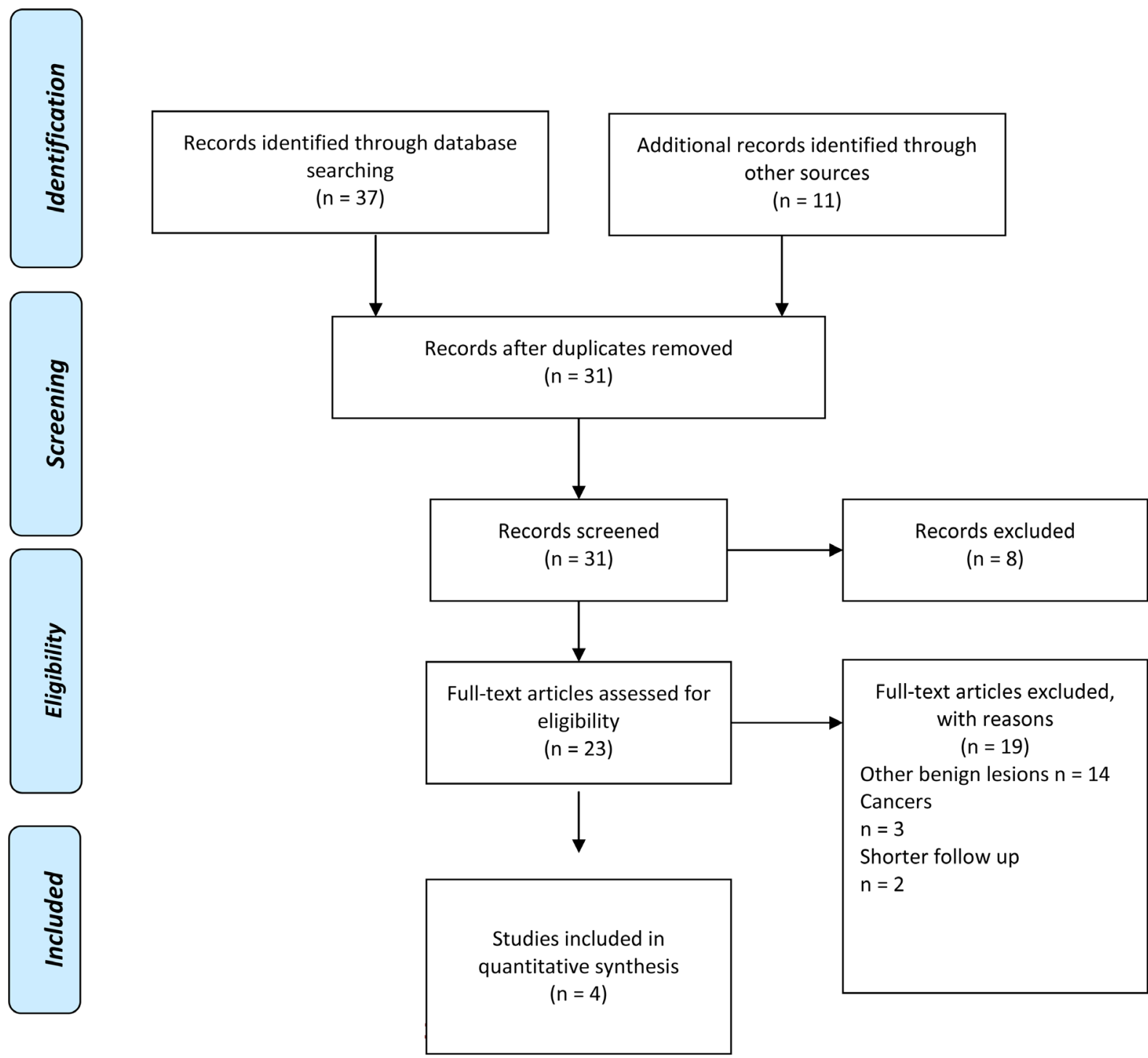

Figure 1. PRISMA flow diagram for systematic review of the 'Efficacy and Safety of Ultrasound Guided Vacuum-Assisted Excision of Fibroadenomas.

The technical detail of the procedure is not significantly different between different studies. It consists of an ultrasound guided localization of the lesion followed by infiltration of a local anesthetic agent. A skin incision measuring a few millimeters is made to accommodate the biopsy needle. The mammotome needle gauge $8 \mathrm{G}, 10 \mathrm{G}$ or $11 \mathrm{G}$ is introduced and positioned below the lesion. The suction mechanism in the biopsy device sucks the lesion into the needle chamber where the knife cuts a fragment of it. The biopsy fragment is sucked out of the needle and collected for histology. The aim is to remove the lesion in fragments until it is completely removed as confirmed by ultrasound. Pressure is applied to the lesion site for $5-10$ minutes for hemostasis and the skin incision covered with sterile dressing. The procedure time ranged from $10-60$ minutes. The main contraindications for vacuum-assisted biopsy includes allergy to anesthetic agent and reduced coagulation especially with an INR more than 2.5 
in patients on Warfarin. Antiplatelet therapy with either aspirin or clopidogrel can be continued because the cardiovascular risk of stopping them may outweigh the risk of bleeding and hematoma arising from the procedure [19].

A complete excision of the FA was achieved in 465 out of 520 cases (89.4\%). In two of the studies where data were available, complete excision rate was $100 \%$ (87/87) when the lesion was less than $1.5 \mathrm{~cm}$ [17] [18], but reduced to $61 \%$ when they were between 1.5 and $2 \mathrm{~cm}$ (50/82) [17] [18].

Apart from the size of the fibroadenoma, other commonly cited reasons for incomplete excision or abandoning the procedure were hemorrhage and location of the FA. In the whole series, there were $12(2.3 \%)$ cases of significant hemorrhage. Pietrzyk G. et al. [15] recorded 4 cases of profuse bleeding that required additional pressure, anti-hemorrhagic drugs and 24 hours observation while Polom K. et al. [16] recorded 2 cases of heavy hemorrhage with a surgical revision needed in one of them. There were four lesions measuring between 1.51 and $2 \mathrm{~cm}$ that could not be resected because of bleeding [18].

Pietrzyk et al. [15] in their analysis of factors that may account for incomplete excision noted that only the size of the tumor was significant. The location of the lesion in the breast, (para-fascia and subcutaneous, quadrant localization) and the operator had no effect on the completeness of the excision [15]. Polom $\mathrm{K}$ et al. [16] however were unable to remove a $5 \mathrm{~mm}$ FA because of its para fascial location and two others because of the combination of the similar para-fascia location and the large sizes.

Other significant complications included severe ecchymosis in 13 out of 113 patients that resolved [17] and two cases of pneumothorax that were managed conservatively without the need for chest drainage. Pain, minor skin bruise, minor bleeding and hematoma were not regarded as being significant. There were no reported cases of infection.

The histology of the resected 365 specimen from 3 case series where reported confirmed FA in 324 (88.7\%), 27 other benign lesions, 2 cases of invasive breast cancer and 2 pre-invasive cancer (lobular carcinoma in situ, lobular carcinoma in situ +FA).

\section{Discussion}

Percutaneous large core biopsy is established as a reproducible and reliable alternative to open surgical biopsy [20]. Vacuum-assisted biopsy systems have been used in USA since 1995 for breast biopsies and its superiority over traditional 14 gauge needle core biopsy in eliminating the need for multiple insertions, reducing false negative results and epithelial displacement is also well established [21]. It is particularly useful in biopsy/excision of small lesions of indeterminate nature (B3), areas of microcalcification, inconclusive histology or discordance on needle core biopsy. It was cleared by the U.S. Food and Drug Administration (FDA) to be used in excision of FA in 2003. Open surgical excision of FA, when indicated remains the gold standard.

Excision of a FA may be needed if it is growing in size, patients older than 35 
years; it is large enough to distort the breast shape, when a phyllodes tumor cannot be definitely ruled out or because of patient's request or anxiety. Generally in terms of size, FAs are excised in the UK only if larger than $30 \mathrm{~mm}$, otherwise they are observed. Some of them do regress and may disappear while others may remain static or grow in size.

The included studies in this review are of low quality as per GRADE [13] criteria, being mostly case series with potential for bias and confounding factors. The combined studies demonstrated that vacuum assisted excision appeared safe and effective in excising small fibroadenomas $(<15 \mathrm{~mm})$ with the complete excision rate approaching $100 \%$. Complete excision rate is reduced to $61 \%$ with sizes between 1.6 and $2 \mathrm{~cm}$, and to $0 \%$ when larger than $2 \mathrm{~cm}$. This makes UGVAE ineffective in most situations where a FA needs to be removed in the modern day breast surgery practice. Fine et al. [22] reported a high success rate excision of benign breast lesions up to $3 \mathrm{~cm}$ including but not limited to FA. FA treated with UGVAE is prone to recurrence. Grady et al. [23] recorded an overall recurrence rate of $15 \%(8 / 52)$ with an actuarial recurrence rate of $33 \%$ at 59 months following treatment. These were exclusively in lesions that measured more than $2 \mathrm{~cm}$ at initial presentation, necessitating further treatment or long-term surveillance. UGVAE was considered inappropriate for FA greater than $2 \mathrm{~cm}$ in diameter because of the greater chance of recurrence [20]. The mechanism of recurrence of an apparently completely excised lesion appears to be regrowth of retained fragments not detected by ultrasound at the time of excision [20].

The most common serious complication was hemorrhage which was significant in $2.3 \%$ of cases with some needing additional measures to stop the bleeding. This included blood transfusion, overnight admission and a case of surgical revision. There were two cases of pneumothorax.

\section{Conclusion}

This systematic review suggests that UGVAE is safe and effective in the excision of smaller FA, but there is no evidence of its effectiveness when FA size is approaching $20 \mathrm{~mm}$ or over. There is no published good quality study that compared open versus UGVAE excision of FA. A well designed case controlled or a randomized control is needed to demonstrate the safety and effectiveness of UGVAE especially those larger than $2 \mathrm{~cm}$ when ordinarily excision may be considered.

\section{References}

[1] Carty, N.J., Carter, C., Rubin, C., Ravichandran, D., Royle, G.T. and Taylor, I. (1995) Management of Fibroadenoma of the Breast. Annals of the Royal College of Surgeons of England, 77, 127-130.

[2] Smallwood, J.A., Roberts, A., Guyer, D.P. and Taylor, I. (1991) The Natural History of Fibroadenoma. British Journal of Pathology, 95, 614-622.

[3] Pick, P.W. and Iossifides, I.A. (1984) Occurrence of Breast Carcinoma within a Fibroadenoma. A Review. Archives of Pathology \& Laboratory Medicine, 108, 590 594. 
[4] Dupont, W.D., Page, D.L., Parl, F.F., et al. (1994) Long-Term Risk of Breast Cancer in Women with Fibroadenoma. The New England Journal of Medicine, 331, 10-15. https://doi.org/10.1056/NEJM199407073310103

[5] Sanders, L.M. and Rana, S. (2015) The Growing Fibroadenoma. Acta Radiologica Open, 4, 1-5. https://doi.org/10.1177/2047981615572273

[6] Dixon, J.M., Dobie, V., Lamb, J., Walsh, J.S. and Chetty, U. (1996) Assessment of the Acceptability of Conservative Management of Fibroadenoma of the Breast. British Journal of Surgery, 83, 264-265. https://doi.org/10.1002/bjs.1800830238

[7] Willett, A.M., Michell, M.J. and Lee, M.J.R. (2010) Best Practice Diagnostic Guidelines for Patients Presenting with Breast Symptoms. Department of Health.

[8] Kovatcheva, R., Zaletel, K., Jordan Vlahov, J. and Stoinov, J. (2017) Long-Term Efficacy of Ultrasound-Guided High-Intensity Focused Ultrasound Treatment of Breast Fibroadenoma. Journal of Therapeutic Ultrasound, 5, 1. https://doi.org/10.1186/s40349-017-0083-1

[9] Yang, B.R., Kim, H.J., Shin, K.M., et al. (2015) Serial Ultrasound Findings after Laser Ablation for Benign Breast Lesions on Long-Term Follow-Up: Implications for Evaluation of Procedural Success. Photomedicine and Laser Surgery, 33, 404-408. https://doi.org/10.1089/pho.2015.3932

[10] Hahn, M., Pavlista, D., Danes, J., Klein, R., Golatta, M., Harcos, A., et al. (2013) U1trasound Guided Cryoablation of Fibroadenomas. Ultraschall Med, 34, 64-68.

[11] Baez, E., Huber, A., Vetter, M. and Hackeloer, B.J. (2003) Minimal Invasive Complete Excision of Benign Breast Tumors Using a Three-Dimensional Ultrasound Guided Mammotome Vacuum Device. Ultrasound in Obstetrics \& Gynecology, 21, 267-272.

[12] NICE (2006) Image-Guided Vacuum-Assisted Excision Biopsy of Benign Breast Lesions (IPG156). https://www.nice.org.uk/guidance/ipg156/resources

[13] Gordon, H.G., Andrew, D.O., Gunn, V., et al. (2011) GRADE Guidelines: 4. Rating the Quality of Evidence-Study Limitations (Risk of Bias). Journal of Clinical Epidemiology, 64, 407-415. https://doi.org/10.1016/j.jclinepi.2010.07.017

[14] Moher, D., Liberati, A., Tetzlaff, J., Altman, D.G., The PRISMA Group (2009) Preferred Reporting Items for Systematic Reviews and Meta-Analyses: The PRISMA Statement. PLoS Med, 6, e1000097. https://doi.org/10.1371/journal.pmed.1000097

[15] Pietrzyk, G., Nowicki, J., Bojarski, B., Kedzierski, B., Wysocki, A. and Prudlak, E. (2007) Mammotome HH Biopsy-The Future of Minimal Invasive Breast Surgery? Polish Journal of Radiology, 72, 19-23.

[16] Polom, K., Murawa, D., Nowaczyk, P., Adamczyk, B., Giles, E., Fertsch, S., Michalak, M. and Murawa, P. (2011) Vacuum-Assisted Core-Needle Biopsy as a Diagnostic and Therapeutic Method in Lesions Radiologically Suspicious of Breast Fibroadenoma. Reports of Practical Oncology and Radiotherapy, 16, 32-35.

[17] Wu. Y.K., Huang, Y.M., Chou, A.S.B., et al. (2005) Management of Breast Fibroadenomas by Ultrasound-Guided Vacuum-Assisted Biopsy-Three Years' Experience. Tzu Chi Medical Journal, 17, 405-408.

[18] Sperber, F., Blank, A., Mester, U., Flusser, G., Klausner, J. and Lev-Chelouche D. (2003) Diagnosis and Treatment of Breast Fibroadenomas by Ultrasound-Guided Vacuum-Assisted Biopsy. Archives of Surgery, 138, 796-800.

https://doi.org/10.1001/archsurg.138.7.796

[19] The RCR Breast Group. Protocol for Breast Biopsy in Patients Taking Anticoagulant and Antiplatelet Therapy.

https://www.bsbrsociety.org/files/8313/9895/6729/biopsy_guidelines_jul_2012.pdf 
[20] Parker, S.H., Burbank, F., Jackman, R.J., Aucreman, C.J., Cardenosa, G., Cink, T.M., Coscia Jr., J.L., Eklund, G.W., Evans, W.P., Garver, P.R., et al. (1994) Percutaneous Large-Core Breast Biopsy: A Multi-Institutional Study. Radiology, 193, 359-364. https://doi.org/10.1148/radiology.193.2.7972743

[21] Parker, S.H., Klaus, A.J., McWey, P.J., Schilling, K.J., Cupples, T.E., Duchesne, N., Guenin, M.A. and Harness, J.K. (2001) Sonographically Guided Directional Vacuum-Assisted Breast Biopsy Using a Handheld Device. AJR American Journal of Roentgenology, 177, 405-408. https://doi.org/10.2214/ajr.177.2.1770405

[22] Fine, R.E., Boyd, B.A., Whitworth, P.W., Kim, J.A., Harnes, J.K. and Burak, W.E. (2002) Percutaneous Removal of Benign Breast Masses Using a Vacuum-Assisted Hand-Held Device with Ultrasound Guidance. The American Journal of Surgery, 184, 332-336. https://doi.org/10.1016/S0002-9610(02)00951-0

[23] Grady, I., Gorsuch, H. and Wilburn-Bailey, S. (2008) Long-Term Outcome of Benign Fibroadenomas Treated by Ultrasound-Guided Percutaneous Excision. The Breast Journal, 14, 275-278. https://doi.org/10.1111/j.1524-4741.2008.00574.x

Submit or recommend next manuscript to SCIRP and we will provide best service for you:

Accepting pre-submission inquiries through Email, Facebook, LinkedIn, Twitter, etc. A wide selection of journals (inclusive of 9 subjects, more than 200 journals)

Providing 24-hour high-quality service

User-friendly online submission system

Fair and swift peer-review system

Efficient typesetting and proofreading procedure

Display of the result of downloads and visits, as well as the number of cited articles

Maximum dissemination of your research work

Submit your manuscript at: http://papersubmission.scirp.org/

Or contact ojrad@scirp.org 